\title{
The Contribution of School Climate and Teaching Quality to the Improvement of Learning Achievements, According to an External Evaluation System
}

\author{
Noga Magen-Nagar*, Dana Azuly \\ Gordon College of Education, Haifa, Israel \\ Email: "nogamagen@gmail.com, danaaz101@gmail.com
}

Received 1 May 2016; accepted 15 August 2016; published 18 August 2016

Copyright (C) 2016 by authors and Scientific Research Publishing Inc.

This work is licensed under the Creative Commons Attribution International License (CC BY).

http://creativecommons.org/licenses/by/4.0/

(c) (i) Open Access

\begin{abstract}
The goal of the current research is to evaluate the contribution of school climate and teaching quality to the improvement of students' learning achievements in elementary schools and junior high schools, according to a national external evaluation system, the measurements of school efficiency and growth tests (MEITZAV). 60 schools took part in the research, including 158 th grades and 157 8th grades. The information about their achievements was taken from the open database of the Ministry of Education. The research findings show a decline in students' perception of the quality of teaching and school climate, the higher the students' grade. In addition, school climate and teaching quality were found to contribute to learning achievements both in elementary school and junior high school, and that the contribution is more meaningful in math and less in Native Language discipline. The main conclusion is that it is important to allocate resources and equip the educational staff with tools in order to improve the quality of teaching and school climate, in junior high schools particularly. These findings show that additional research is necessary to allow deeper understanding of the effect of school climate and teaching quality on achievement at the single student level.
\end{abstract}

\section{Keywords}

School Climate, Teaching Quality, Learning Achievements, External Evaluation

${ }^{*}$ Corresponding author.

How to cite this paper: Magen-Nagar, N., \& Azuly, D. (2016). The Contribution of School Climate and Teaching Quality to the Improvement of Learning Achievements, According to an External Evaluation System. Creative Education, 7, $1773-1784$. http://dx.doi.org/10.4236/ce.2016.713181 


\section{Introduction}

Many countries in the world have developed educational indicator systems that were designed to determine the quality of education systems and schools, in order to affect the functioning of the educational staff and the production of the schools while demanding accountability (Hosp \& Ardoin, 2008; Darling-Hammond, 2004). In Israel, the external and extensive tests provide follow-up, monitoring and management tools for educational systems and organizations. The extensive tests system assists in defining the standards expected of the students academically, tests their knowledge and is meant to increase the teachers' and students' commitment to learning achievements, all this with the goal of reducing gaps. Usually the tests are standardized and check an extensive amount of learning materials, and are designed professionally according to accepted psychometric and pedagogical rules (Birenbaum, Kimron, \& Shilton, 2011).

\section{External Evaluation System-MEITZAV}

The MEITZAV (Hebrew acronym for "School Growth and Efficiency Measures”) system is an objective indicator system for evaluating elementary and junior high schools in Israel. The MEITZAV is part of the educational evaluation field that includes different aspects, such as learning achievements, school relationships, school climate, organization and standpoints. The MEITZAV system examines many aspects and reflects the perception that a school is a combination of many parts that interact with each other (Beller, 2013). The results of the MEITZAV tests allow a wide and reliable view of the educational organizations' functioning, and include information about students' achievements, school climate, learning, teaching and students' feelings. Since the MEITZAV is national and uniform, it contributes to the synchronization between all the education departments, and therefore to the goals achievement of the education system in general. The MEITZAV is done by RAMA (Hebrew acronym for "The National Authority of Measurement and Evaluation in Education”), a professional and independent authority attached to the Ministry of Education (RAMA, 2013).

\subsection{Students' Achievements}

At the declaration level, the Israeli education system puts the student and his needs at the center of the educational work, in accordance to Vygotsky's approach (2004). However, the students arrive to school with different biological characteristics, family relations history, learning ability and life skills, therefore school cannot provide every student's needs equally (Lee \& Smith, 1995; Prevatt \& Kelly, 2003). Thus, there are still students that the education system does not provide for their needs and does not allow them to fulfil themselves, and so it affects the level of learning achievements. In Israel, it is aspired that each school would address the diversity between students and invest in each student according to their needs, so that all students would reach high achievements regardless of their socio-economic background characteristics (Ministry of Education, 2013a).

Quality teachers that work to increase the level of achievements, the self-efficacy and feeling of success for all students, can narrow the gaps in learning results of students from different socio-economic backgrounds, promote learning, increase learners' achievements and strengthen the relations and care between students, teachers and the whole school community (Borman \& Kimball, 2005).

The achievements test of the MEITZAV tool focus on four core subjects: Mother Tongue (Hebrew/Arabic), Math, English, and Science and Technology. The tests are designed in full adequacy to the different subjects' curricula. The development of the test in each subject is accompanied by a steering committee that includes the subject coordination inspector or his representative, and also academia members, inspectors, guides and subject teachers. The achievements in the MEITZAV tests are meant to measure the extent to which the elementary students (grades 2 and 5) and junior high school students (grade 8) meet the level of requirements expected according to the mother tongue curriculum (RAMA, 2013).

The MEITZAV achievement tests are held in each of the subject areas in a four-year cycle. The schools are tested every two years by external tests in only two subjects: Math and Mother Tongue (Hebrew/Arabic) or English and Science and Technology, and two years later they are tested on the other two subjects. Thus, each school is tested in an external MEITZAV test in each subject area (at the relevant class levels) once every four years. Additionally, these tests are held as internal tests at the same subject areas on the other three years (RAMA, 2013). 


\subsection{School Climate}

"School Climate" is a multi-dimensional term that deals with the relationships system in the sociological, psychological and pedagogical areas, by which learning occurs and affects the achievements and learners' positions (Fraser, Fisher \& McRobbie, 1996). The main approach in the current research is the ecological approach, according to which, research of the learning environment addresses school as a social environment, and school climate as it is perceived by the individuals belonging to the educational environment and are active within it. Students and teachers are the main partners in the conduct of the school. The subjective interpretation they give to the school systems' conduct and their interaction, determines the school climate, under the assumption and understanding that the atmosphere is based on the perception of the individual within the group collective (Ju-Sen \& Chauyun, 2014).

The school climate is affected by different factors that make the learning environment: the physical structure of the school, the organizational structure that guards its goals, teachers' perception regarding their organization's environment (principal and students), the authority structure at the school, the students' socio-economic background, and the regard to the activities at the school (Hoy \& Miskel, 2005). The researchers believe, that in order to change the school organization, a positive and supportive climate should be created, a climate in which the teachers and school principal focus on processes of progression, flexibility, and student's success (Lee \& Burkam, 2003; Purkey \& Smith, 1983). A positive climate affects students' motivation and their involvement, improves the class learning and is expressed by a pleasant learning atmosphere, that encourages free expression, experience, taking risks, mutual support, knowledge transference, sharing, and preserving knowledge. The atmosphere and classroom interaction characteristics have a crucial effect on the individual's behavior (Afari, Aldridge, Barry, Fraser, \& SweKhine, 2013; Ju-Sen \& Chauyun, 2014).

Evaluation of school climate by the MEITZAV tests is based on international indicators (OECD, 2013). It includes feelings of belonging and security at school, friendships in the class and teacher-students relationships. It seems that the definition of school climate includes questions that reflect the humanistic approach to motivation as defined in Maslow's theory of need (feelings of safety, closeness and care). The goal of this evaluation is to provide school principals and the Ministry of Education Headquarters a diverse, inclusive view, in order to locate the relative strength and weakness points of the school and the entire system in each of the subjects over time.

Researchers have found a relationship between the school and classroom climate and learning achievements. A positive climate contributes to a positive self-evaluation of the students, gives them confidence, encourages co-operation and promotes belonging and cohesiveness (Shannon \& Bylsma, 2008). Additional researchers show that a positive school climate affects the improvement of learning achievements, even beyond the effect of the student's socio-economic background (Rumberger \& Palardy, 2005).

\subsection{The Quality of Teaching}

The quality of teaching has received much attention for many years. Education researchers deal with the question: What is good teaching, and what is its effect on students' achievement and behavior? (Berliner, 2005; Darling-Hammond \& Youngs, 2002; Fenstermacher \& Richardson, 2005; Fullan, Hill \& Crevola, 2006). The quality of teaching expresses the understanding of the required knowledge and skills. It includes not only "what” but also "how" to teach, in a way that will allow students to reach the required standard level. Teaching is a combination of teacher-student interactions about contents in a certain context. The teaching has quality when it focuses on each student's needs (Fullan et al., 2006).

The quality of teaching is measured on two aspects: "effective teaching" and "good teaching". Effective teaching is about reaching learning achievements and meeting standards, and the way the teacher makes his knowledge accessible to the knowledge processes of those who don't understand, while good teaching is about the way the teacher regards his students, and using the teacher's skills to assist students in their learning. A quality teacher will have a combination of effective and good teaching (Berliner, 2005).

Many research findings consistently show the relationship between the family, social, economic and cultural background and students' achievements. The learning achievements of many of the students who grow up in poor families do not reflect the full potential of their learning abilities (Lee \& Burkam, 2003). On the other hand, the teacher's behavior affects the students and can narrow gaps in the learning results of students of different socio-economic backgrounds (Darling-Hammond \& Pecheone, 2010). The findings of a comprehensive research 
in Israel show that the quality of teaching affects the chances of dropping out of school more than the student's personal attributes, since the $4^{\text {th }}$ grade (Magen-Nagar \&Shachar, 2016).

The measurements of teaching quality in the MEITZAV tests are based on international indicators (OECD, 2013). These indicators assess the quality of teaching and learning processes inside and outside of the classroom, and their effects on the students. These are indicators related to pedagogical processes between teachers and students, emotional-motivational aspects that the learner experiences and the organizational running of the school (RAMA, 2013). The quality of teaching includes the pedagogical environment that emphasizes the teacher's support of the students in the class, addressing students' diversity, and additional means that affect learning without direct mediation of the teacher, such as ICT and homework.

In general, we can say that research show that a student's perception of the school climate and teaching quality is becoming more negative since the beginning of his studies at elementary school until his high-school graduation (Magen-Nagar \& Shachar, 2016; Shannon \& Bylsma, 2008). In the lower grades the climate is perceived as positive and encouraging involvement and participation. The higher the grade level, the more focused teaching is on achievements and less on pedagogical processes and this fact affects the level of interest in the studies and the level of student's satisfaction, regardless of their personal attributes. In addition, the higher the grade, the more competitive school is becoming, the subject material is more abstract, and there is a requirement to standardized tests that do not consider the unique and personal needs of students. As a result, the learning achievements do not match the students' abilities.

\section{The Goal of the Research}

The goal of the current research is to evaluate the level of contribution of teaching quality and school climate to the improvement of students' achievements in elementary and junior high schools, according to external evaluation-MEITZAV.

\section{The Research Hypotheses}

1) The higher the quality of teaching, the higher the achievements of students would be in the MEITZAV tests.

2) The more positive the school climate, the higher the achievements of students would be in the MEITZAV tests.

3) Elementary school students ( $5^{\text {th }}$ grade) will perceive the teaching quality as higher than junior high school students $\left(8^{\text {th }}\right.$ grade).

4) Elementary school students $\left(5^{\text {th }}\right.$ grade) will perceive the school climate as more positive than junior high school students ( $8^{\text {th }}$ grade).

\section{Method}

The external MEITZAV is held at a school once every four years according to "MEITZAV clusters" that refer to the division of schools in Israel into four equal and representative groups (RAMA, 2013). The external MEITZAV tests were held in April-May 2011. Schools from clusters A and C participated: 1094 schools, 4352 classes and 117,130 students (RAMA, 2013).

The current research is based on the results of the external MEITZAV tests in Native Language and Math for the school year of 2011. Cluster C schools participated that year. The data for the research was retrieved from the open to the public database of the Ministry of Education (Ministry of Education, 2013b).

\subsection{Participants}

60 schools participated in the research, out of which 30 were elementary schools including $1585^{\text {th }}$ grades and 4749 students, and 30 junior high schools, $1578^{\text {th }}$ grades and 4734 students. The schools were sampled randomly. Schools from each county were sampled, of different inspection types and different class levels, with an attempt to ensure heterogeneity and appropriate and equal representation of the general population.

\subsection{Research Tools}

The MEITZAV tools are the research tools. The goal of the MEITZAV tools is to assess the level of student 
control of the knowledge required in the different topics, thinking skills, and also assess their positions about school climate and pedagogical environment (RAMA, 2013). The MEITZAV tools are divided into two parts: the first part includes learning achievements tests, and the second part includes self-report questionnaires to assess the school climate and pedagogical environment. The score range of the MEITZAV tools is between 0-100.

\subsubsection{Achievement Tests}

\section{1) Achievement Tests in Language}

The Hebrew tests are designed to assess the level of control of the students in language education according to the Hebrew curriculum. The test is only for Hebrew speakers. The topics in the tests were: reading comprehension, written expression and grammar and meta-grammar. The test for the $5^{\text {th }}$ grade included 25 questions and tested reading comprehension through questions referring to texts of three genres: story, informational text and practical text. The comprehension questions in the test checked three aspects of understanding: the explicit meaning in the text; the implicit meaning in the text; application, evaluation and critical thinking. The test for the $8^{\text {th }}$ grade included 26 questions, and checked the reading comprehension through questions referring to texts of three genres: conviction, informational text and practical text. The comprehension questions in the test checked three aspects of understanding: locating information and re-organizing it; interpretation and drawing conclusions; evaluation and critical thinking: all in accordance to the $8^{\text {th }}$ grade curriculum (RAMA, 2013). The test took 90 minutes.

\section{2) Achievement Tests in Math}

The Math tests check the level of student control over the subjects of the curriculum and thinking skills in different levels: knowledge and identification, algorithmic thinking, process thinking (application and arithmetic comprehension), open search and reasoning. The test for the $5^{\text {th }}$ grade included 40 questions and checked the following topics: whole numbers, fractions, geometry and measurement. The test for the $8^{\text {th }}$ grade included 25 questions and checked the following topics: number, algebra and geometry (RAMA, 2013). The test took 90 minutes.

\subsubsection{The School Climate and Pedagogical Environment Questionnaires}

The school climate and pedagogical environment questionnaires deal with a wide range of areas of school life, as perceived by the students. The questionnaires check the atmosphere and relationships at school and the quality of teaching at school. The questionnaires were developed by a team of RAMA researchers and a number of university researchers, and they draw from a number of main sources: a. focus groups with school principals, b. meetings with position holders from different subject areas in the education system, c. interviews with researchers from the academia, d. a combination of knowledge taken from current academic literature that deals with the theoretical terms used today to assess and measure school climates in Israel and the world. The first version of the questionnaires underwent face validation by experts in the field. At the end of this stage four questionnaires were formed: school climate questionnaire and pedagogical environment questionnaire, each according to students report and teachers report. School climate questionnaire included 28 items and the pedagogical environment questionnaire included 30 statements. In this study, the pedagogical environment questionnaire was used to measure the quality of teaching. At the second stage, the questionnaires underwent construct validation by a series of factor analysis, and their reliability was tested (RAMA, 2013). The participants were required to state how much they agree with the statement, in a scale ranging from "highly agree" (5) to "highly disagree" (1). For different statements about the same topic, one total measurement was calculated, and an average of the percentages of people agreeing with the statements about the same topic was calculated.

Table 1 presents the results of the learning achievements tests, the school climate and quality of teaching in 60 schools including $3155^{\text {th }}$ and $8^{\text {th }}$ grades.

Table 1 shows that the internal reliability of the different data is high, and ranging between 0.77 and 0.93 . Therefore we can conclude that enough data was gathered in order to perform reliable statistical manipulations for drawing conclusions.

\section{Findings}

In order to test the first hypothesis, that the higher the quality of teaching, the higher the achievements, Pearson correlation was calculated between those two variables. The correlation shows a positive weak significant rela- 
tionship $(r=0.246 ; p<0.05)$ between the quality of teaching and achievements. That is, the higher the quality of teaching, the higher the general level of achievement. In order to evaluate the effect of the differences of levels of quality of teaching on achievements, the participants were divided into 3 equal groups according to the scores of the teaching quality (Table 2, Table 3 ).

Through a one-way multivariate analysis of variance (MANOVA), a test was done for significant differences in the Native Language and Math achievements between the different levels of teaching quality (Table 3).

Table 3 shows the general model of the effect of teaching quality on achievements, that represents the total score of Math and Language. The analysis shows a significant effect of the level of teaching quality on the total score $(F(4,112)=3.69, p<0.01$, Eta2 $=0.117)$. Later, one way analysis of variance (ANOVA) was done in order to evaluate the source of the significance, a significant difference in the Math score was found $(F(2,57)=$ $5.04, p<0.01, \operatorname{Eta} 2=0.15$ ).

Then, paired comparison analysis according to Scheffe was performed, in order to trace the source of the differences between the levels of teaching quality. A significant difference was found in the Math score between the low level and the high level in teaching quality. However, in Language, no significant effect was found between the different levels of teaching quality $(F(2,57)=0.532, p>0.05$, Eta2 $=0.018)$. As can be seen in Figure 1, in Math there is a significant difference between the achievements received for the different levels of teaching quality, however, in Native Language there is no significant difference in the achievements according to the levels of the teaching quality. The hypothesis was partially reinforced.

In order to test the second hypothesis, that the more positive the school climate, the higher the achievements, Pearson correlation was calculated between school climate and learning achievements. The correlation found shows a positive, medium to high, significant correlation $(\mathrm{r}=0.346 ; p<0.01)$ between school climate and

Table 1. The results of the learning achievements, school climate and teaching quality $(n=60)$.

\begin{tabular}{ccccc}
\hline & M & SD & Range & Cronbach's Alpha \\
\hline Native Language & 72.3 & 8.9 & $34.6-86.6$ & 0.93 \\
Math & 54.6 & 12.0 & $18.0-75.7$ & 0.77 \\
Achievements & 63.5 & 9.7 & $26.3-80.2$ & 0.89 \\
School Climate & 62.0 & 16.6 & $27.8-97.2$ & 0.93 \\
Teaching Quality & 57.7 & 14.4 & $34.0-89.3$ & 0.93 \\
\hline
\end{tabular}

Table 2. The scores of teaching quality indicator in three levels in elementary and junior high schools.

\begin{tabular}{cccc}
\hline Quality of Teaching & Quality of Teaching Score & Elementary Schools $\left(5^{\text {th }}\right.$ grade) & Junior high schools $\left(8^{\text {th }}\right.$ Grade $)$ \\
\hline Low Level & $34-49$ & 0 & 20 \\
Medium Level & $49.25-65$ & 10 & 0 \\
High Level & $65.5-89.25$ & 20 & 30 \\
Total & & 30 & 0 \\
\hline
\end{tabular}

Table 3. Learning achievements according to levels of quality of teaching: means, sd, $f$ values and effect size.

\begin{tabular}{|c|c|c|c|c|c|c|c|c|c|}
\hline & \multicolumn{2}{|c|}{$\begin{array}{l}\text { Low Level } \\
(\mathrm{N}=20)\end{array}$} & \multicolumn{2}{|c|}{$\begin{array}{l}\text { Medium Level } \\
\quad(\mathrm{N}=20)\end{array}$} & \multicolumn{2}{|c|}{$\begin{array}{l}\text { High Level } \\
(\mathrm{N}=20)\end{array}$} & \multirow[t]{2}{*}{$\mathrm{F}$} & \multirow[t]{2}{*}{$p$} & \multirow[t]{2}{*}{ Eta2 } \\
\hline & $M$ & $S D$ & $M$ & $S D$ & $M$ & $S D$ & & & \\
\hline Native Language & 70.7 & 9.0 & 73.4 & 11.1 & 72.9 & 8.9 & 0.532 & 0.590 & 0.018 \\
\hline Math & b49.1 & 11.2 & ab54.5 & 13.7 & a60.4 & 8.3 & 5.044 & 0.010 & 0.150 \\
\hline Learning Achievements-total score & 59.9 & 8.9 & 63.9 & 12.0 & 66.6 & 6.4 & 3.687 & 0.009 & 0.117 \\
\hline
\end{tabular}


achievements. That is, the higher the score of the school climate, the higher the general level of learning achievements. In order to test the differences between levels of school climates, the participants were divided into 3 equal groups (Table 4).

Through a one-way multivariate analysis of variance (MANOVA), a test was done for significant differences in the Native Language and Math achievements between the different levels of school climate (Table 5).

Table 5 shows the general model of the effect of the levels of school climate on learning achievements. The analysis show a significant effect, and that the levels of school climate indeed affect the learning achievements $(\mathrm{F}(4,112)=4.901, p<0.001$; Eta2 $=0.149)$. Later, one way analysis of variance (ANOVA) was done in order to evaluate the source of the significance, a significant difference in the Math score was found $(F(2,57)=6.144$, $p<0.01$, Eta2 $=0.177$ ). As can be seen in Figure 2, a significant difference in the Math scores was found between the low level and the high level in the school climate. In Language, however, no significant effect was found between the effects of the different levels of school climate $(F(2,57)=0.267, p>0.05$, Eta2 $=0.009)$. The hypothesis was partially reinforced.

In order to evaluate the third hypothesis, that elementary school students $\left(5^{\text {th }}\right.$ graders $)$ will perceive the quality of teaching as higher than junior high school students ( $8^{\text {th }}$ graders), $\mathrm{T}$ test for independent samples was done. The analysis revealed significant differences between the schools $(\mathrm{t}(58)=11.003 ; p<0.001$ ), the effect between the two samples is strong (Cohen's $d=2.84)$. That is, Students in elementary schools $\left(5^{\text {th }}\right.$ grade) perceive the teaching quality as higher $(\mathrm{M}=69.40, \mathrm{SD}=9.70)$ than junior high school students $\left(8^{\text {th }}\right.$ grade $)(\mathrm{M}=46.00, \mathrm{SD}=$ 6.39). The third hypothesis was reinforced.

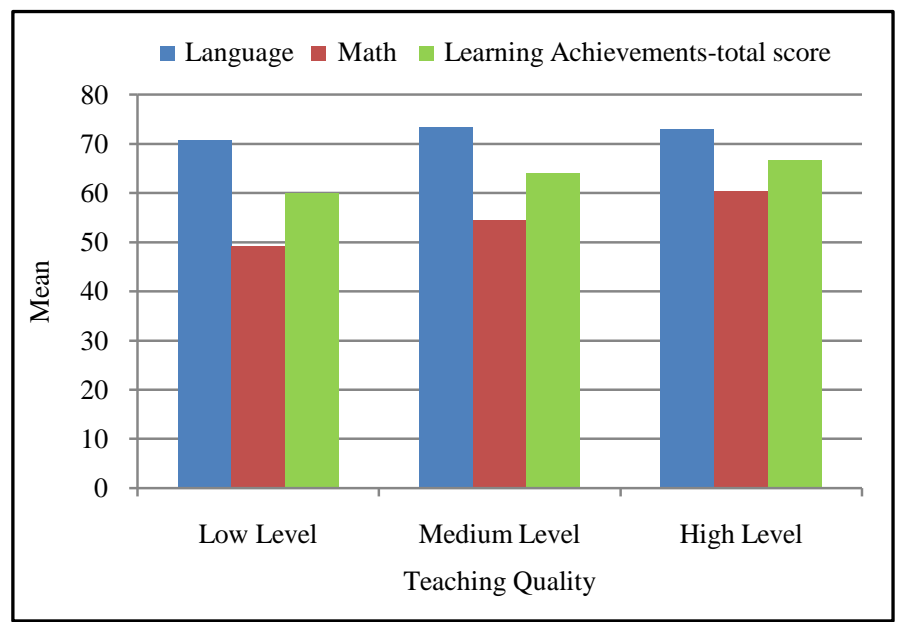

Figure 1. Means of language, math and learning achievements-total score, according to the levels of teaching quality.

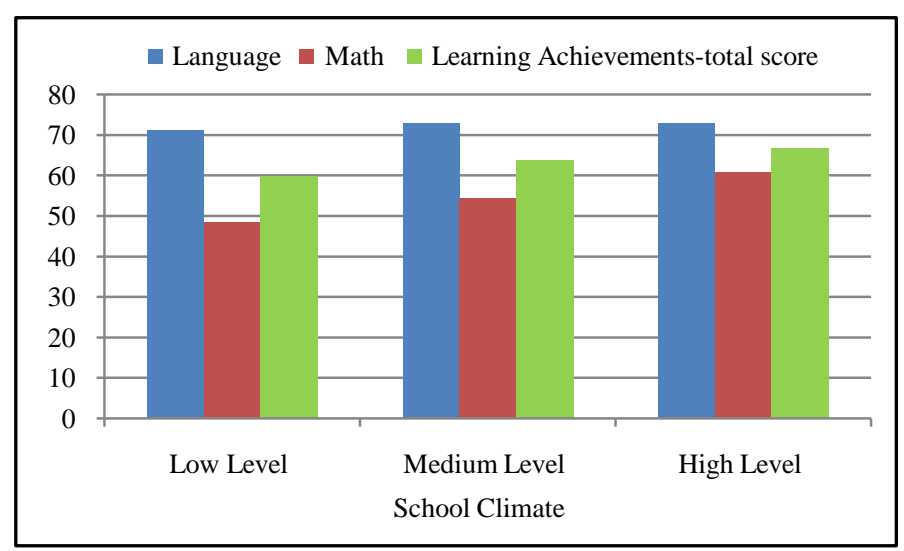

Figure 2. The mean scores in language, math and learning achievements-total score, according to levels of school climate. 
In order to test the fourth hypothesis, that elementary school students $\left(5^{\text {th }}\right.$ grade) will perceive school climate as more positive that junior high school students ( $8^{\text {th }}$ grade) $\mathrm{T}$ test for independent samples was done. The analysis revealed significant differences between the schools $(\mathrm{t}(58)=9.85 ; p<0.001)$, the effect between the two samples is strong (Cohen's $d=2.54)$. That is, Students in elementary schools $\left(5^{\text {th }}\right.$ grade) perceive the school climate as more positive $(\mathrm{M}=75.02, \mathrm{SD}=11.07)$ than junior high school students $\left(8^{\text {th }}\right.$ grade $)(\mathrm{M}=49.02, \mathrm{SD}=$ 9.29). The fourth hypothesis was confirmed. To summarize the differences can be seen in Figure 3.

\section{Discussion}

The research findings show a positive significant relationship between the quality of teaching and students' achievements. These findings are consistent with the literature, that see the relationship between the quality of teaching and learning achievements as very meaningful (Darling-Hammond \& Pecheone, 2010; Tam, 2011). Despite the relationship between the family background, education and job status of the parents, and the students' educational achievements, public school has a substantial ability to affect students' achievements (Lee \& Bur$\mathrm{kam}, 2003)$. Students were found to be functioning according to what is expected of them, therefore if teachers set high expectations of the students, their students reach higher achievements (Magen-Nagar \& Shachar, 2016). When students receive specific information about the gaps in their learning and the chances of improving their work, they receive a clear message from the teacher that they can learn and improve.

Table 4. The scores of school climate indicator in three levels in elementary and junior high schools.

\begin{tabular}{cccc}
\hline School Climate & Scores & $5^{\text {th }}$ Grade & $8^{\text {th }}$ Grade \\
\hline Low Level & $27.8-51.4$ & 0 & 20 \\
Medium Level & $53-69.2$ & 10 & 10 \\
High Level & $69.4-97.2$ & 20 & 0 \\
Total & & 30 & 30 \\
\hline
\end{tabular}

Table 5. Learning achievements according to levels of school climate: means, sd, f values and effect size.

\begin{tabular}{|c|c|c|c|c|c|c|c|c|c|}
\hline & \multicolumn{2}{|c|}{$\begin{array}{l}\text { Low Level } \\
(\mathrm{N}=20)\end{array}$} & \multicolumn{2}{|c|}{$\begin{array}{l}\text { Medium Level } \\
\qquad(\mathrm{N}=20)\end{array}$} & \multicolumn{2}{|c|}{$\begin{array}{l}\text { High Level } \\
(\mathrm{N}=20)\end{array}$} & \multirow{2}{*}{$\mathrm{F}$} & \multirow{2}{*}{$p$} & \multirow{2}{*}{ Eta2 } \\
\hline & $M$ & $S D$ & $M$ & $S D$ & $M$ & $S D$ & & & \\
\hline Native Language & 71.12 & 9.41 & 72.98 & 10.49 & 72.84 & 6.53 & 0.267 & 0.7670 & 0.009 \\
\hline Math & $48.52 b$ & 11.24 & 54.55ab & 12.83 & $60.8 \mathrm{a}$ & 8.76 & 6.144 & 0.0040 & 0.177 \\
\hline Learning Achievements-total score & 59.82 & 9.17 & 63.77 & 11.32 & 66.82 & 7.12 & 4.901 & 0.0010 & 0.149 \\
\hline
\end{tabular}

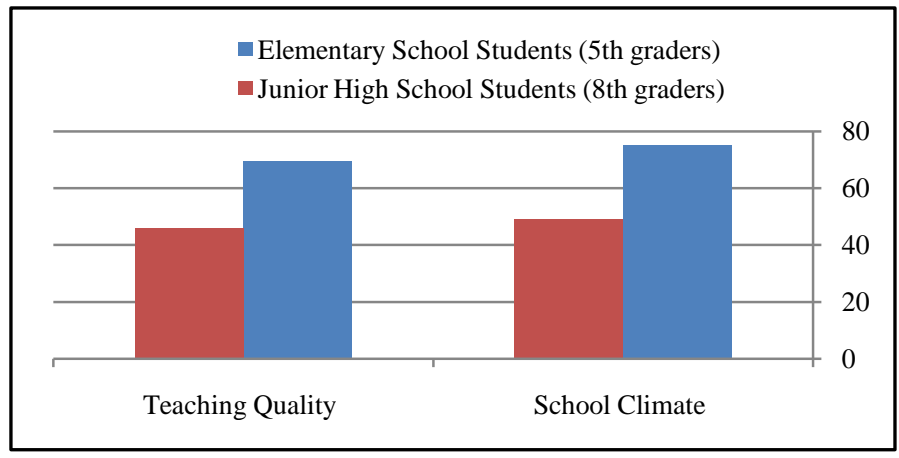

Figure 3. Comparison between the school climate and the teaching quality between elementary school students ( $5^{\text {th }}$ Grade) and Junior high school students $\left(8^{\text {th }}\right.$ Grade). 
The research findings show a positive significant relationship between school climate and students achievements. This is supported by many researches that claim that good climate contributes to increasing the learned stimulation, develops will power to succeed among students, and brings actual improvements in their achievements (Lee \& Burkam, 2003; Purkey \& Smith, 1983). A positive school climate may contribute to students' personal development, positive self-evaluation and secure feeling (Ju-Sen \& Chauyun, 2014). Moreover, the effect of social climate on reaching high learning achievements was found to be beyond the effect of the socioeconomic background.

\subsection{Between Native Language and Math Achievements}

In examination of the general model of the contribution of school climate and the contribution of teaching quality to achievements, a positive significant effect was found for Math, but no significant effect was found for Language. The differences in the subjects' characteristics may offer a possible explanation to this finding. The different skills required for language combine acquired strategies that connect to the student's personal vocabulary and knowledge. This vocabulary is acquired throughout the student's life, it is very affected by the sociocultural environment to which he is exposed from a young age, and he uses it to understand texts and to form answers. In addition, in the reading comprehension process of a written text, there is an interaction between decoding the text and the personal world knowledge that creates the meaning for that reader. Therefore, the effect and contribution of the teacher to the student's achievements is limited only to those acquired learning strategies, therefore the quality of teaching and school environment are limited in their effect on the students' achievements.

The Math subject is a language and culture that requires meticulous thinking structures. In order to cope with the subject, the student has to acquire knowledge of agreed upon symbol systems. This field requires control over strategies, skills and specific procedures that require deep teaching and learning (Schoenfeld, 1985). Math is based on process knowledge that includes knowledge of rules and algorithms for problem solving. This process knowledge involves learning and memorizing the rules required of the student in order to perform different mathematical calculations, and in addition, knowing a net of different terms and understanding the relations between them (Hiebert \& Lefevre, 1986). Most of the Mathematical terms are not taken from the day-to-day life of the students, and the teacher has a central role in the student's learning. It is reasonable to assume that schools with a high level of positive school climate, will maintain efficient and good learning that allow students to reach high scores in tests, and vice versa. Also, in schools where the teachers are of high level of quality, the students reach higher scores. The teachers create a learning environment that provides for different kinds of learners according to their abilities and skills.

Different researchers (Barry \& Muint, 2013) found that classroom climate has a meaningful contribution to Math studies, but they do not provide an explanation for this. Mathematics is a subject that demands precision, responsibility, drill, memorizing and one correct solution. For some of the students the learning involves fear, hesitation and mainly a sequence of failure experiences. A positive climate is expressed in a positive learning atmosphere that expresses flexibility, openness and the ability to develop a sensitive dialogue with all partners of the educational process (Afari et al., 2013; Ju-Sen \& Chauyun, 2014). When a class has a positive climate, the students dare to try, ask and experience, and making mistakes during the learning process is legitimized. When the climate is positive during Math class, the students participate in the class and therefore the learning achievements are improved. In addition, the use of interactive and innovative technological educational means affect the class climate and the quality of teaching, and reflects the teacher's perception of his role and conduct in class. A teacher that will incorporate these tools in Math lesson plans, would mostly incorporate more effective teaching methods that involve understanding performances, active teaching in class and drills that improve the students' achievements in the field. However, in Language, the texts and their comprehension create constant interaction with the student world of content, each student brings his world and experience to the class, and therefore the contribution of the class climate and the class interaction over the student's learning and achievements is limited.

\subsection{The Relationship between the Grade Level and the Perception of School Climate and Teaching Quality}

Researchers agree about the effect and importance of school climate on students' functioning. School climate 
affects the belongingness of students and the development of educational processes. However, research shows that Israeli youth reveals a negative attitude towards school more that the youth in other countries. Israeli youth are not satisfied in school quality of life and their teachers' rapport with them. It is very important that students will perceive school as a positive place and develop positive feelings and standpoints towards it. The older the student, the more negative his perception of the school's quality of life. The student's perception of school and class climate may turn negative from the beginning of his studies at elementary school until his graduation from high school (Shannon \& Bylsma, 2008). This literature review supports the research findings that indicate the existence of a negative strong significant relationship between the grade level and the perception of school climate, and reinforces the fourth hypothesis that there are differences between students of the $5^{\text {th }}$ grade and students of the $8^{\text {th }}$ grade in school climate perception, so that students of the $5^{\text {th }}$ grade will perceive the school climate as more positive that students of the $8^{\text {th }}$ grade.

The higher the grade level, the teaching focuses more on achievement and less on pedagogical processes, and it is likely that this change affects the decline in the teaching quality perception and school climate perception over the years (Magen-Nagar \& Shachar, 2016). Alongside the decline in the teaching quality perception, satisfaction and belongingness, that are part of the school climate perception, also decline. This explanation supports the research findings that showed significant differences between the $5^{\text {th }}$ grade students' perception of the teaching quality and that of the $8^{\text {th }}$ grade students, as assumed. According to the third hypothesis, there are differences between $5^{\text {th }}$ grade students and $8^{\text {th }}$ grade students in the perception of teaching quality, so that $5^{\text {th }}$ grade students will perceive the quality of teaching as higher than $8^{\text {th }}$ grade students.

At elementary school, as part of the teacher's role perception, the homeroom teacher teaches most of the subjects in his homeroom class, he spends much time with his students in the class, and he is the center point in forming the classroom climate. In addition, teachers handle the relationships between students in the class, get involved and assist the relationships between students, and teach behavior norms in the class. This is in addition to the pedagogy and teaching the subject material. In junior high schools, students from a number of elementary schools come together. They come from different academic levels and different types of schools. Some are busy with socialization and finding their place in the new society in addition to the studies, while learning the behavioral and social codes expected of them. Additionally, the systematic-educational perception in junior high school is different than the elementary school: the homeroom teacher spends few hours in his homeroom class. In his place, come a great number of professional subject teachers, whose teaching is similar to a lecture and they focus more on achievement and less on pedagogical and social processes. The combination of these factors affects the belongingness, satisfaction, security, and the students' involvement in learning, and these may be some of the factors that contribute to the decline in the perception of the teaching quality and school climate.

\subsection{Research Limitations}

The current research has a limitation that derives from the fact that the published data in the Ministry of Education website come in the form of school test results, and not the results for every student, so the conclusion drawn is at the school level. Therefore, we cannot draw conclusions at the individual level and deepen the findings, the conclusions and the discussions, and turn them into more meaningful. According to researches and testimonies, the validity of the results of the MEITZAV tests is in doubt, due to misconduct of schools. It is impossible to know whether the school results that were used for this research came from schools that conducted the tests correctly and honestly, and if there was misconduct at the schools, what the true results are for the sample.

\subsection{Future Research}

Following this research, its findings and conclusions, the understanding of the effect of school climate and teaching quality on achievements can be deepened by referring to the different sub-variable level, comparing between the effect level of the contributing factors and designing ways to intervene and improve the school climate.

\section{Conclusion and Recommendations}

School climate and teaching quality contribute to learning achievements, a contribution that is expressed also in 
external, uniform and reliable tests. This effect is expressed in different strengths in the different grade levels and different subject areas. These conclusions are supported by many researches, and they show that it is not only the student's socio-economic background that has the responsibility for his achievements. School has the responsibility and ability to affect students' achievements, therefore the educational staff has the responsibility to try and provide every student with their needs, and improve the perception of the school climate and the perception of teaching quality, in order to allow students to fulfill their potential, even when they come from a low socio-economic background.

The research findings indicate a strong significant difference in the school climate and teaching quality perception between the different grade levels. A decline in the perception of the teaching quality and school climate is apparent. The higher the grade, teaching is becoming more focused on achievements and less on pedagogical processes. In addition, the research supports the claim that school climate and teaching quality contribute to learning achievements. It can be assumed that achievement-focused teaching without quality teaching and good school climate will not ensure the students' success at school. Therefore, it can be concluded that school climate and teaching quality should be an integral part of the school culture in junior high schools as well. It is important that achievements will not become the only goal of junior high school. Due to the characteristics of the early teen years of the junior high school students, the school structure and the changing demands, adapted plans should be implemented to improve the school climate and resources should be allocated to improve teaching quality. Addressing, training and resourcing for equipping the educational staff with tools to improve the school climate and teaching quality at school may contribute to improving the feeling of junior high school students, increase their belongingness, assist the struggling students to perceiver, prevent their dropping out, and contribute to the learning achievements of all school students.

In Mathematics, a significant effect of school climate and teaching quality on student achievement can be seen. The research shows that in junior high school, the perception of teaching quality declines and the achievements of students in general and in math in particular, decline. The contribution of the teaching quality to achievements was reinforced in the research, and that is why teachers should be given tools that are adequate to teaching math in junior high school. Through proper training, where they can acquire the tools and means to deliver quality lessons, and combine quality IC technology alongside the teaching method that fits the class characteristics, all this while maintaining personal rapport and trying to improve the classroom climate.

\section{References}

Afari, E., Aldirge, J. M., Fraser J. B., \& Swe Khine, M. (2013). Students’ Perceptions of the Learning Environment and Attitudes in Game-Based Mathematics Classrooms. Learning Environments Research, 16, 13.

http://dx.doi.org/10.1007/s10984-012-9122-6

Beller, M. (2013). Assessment in the Service of Learning: Theory and Practice. Ramat Gan: RAMA: The National Authority for Measurement \& Evaluation in Education.

Berliner, D. C. (2005). The Near Impossibility of Testing for Teacher Quality. Journal of Teacher Education, 56, $205-213$. http://dx.doi.org/10.1177/0022487105275904

Birenbaum, M., Kimron, H., \& Shilton, H. (2011). Nested Contexts That Shape Assessment for Learning: School-Based Professional Learning Community and Classroom Culture. Studies in Educational Evaluation, 37, 35-48.

http://dx.doi.org/10.1016/j.stueduc.2011.04.001

Borman, G. D., \& Kimball, S. M. (2005). Teacher Quality and Educational Equality: Do Teachers with Higher StandardsBased Evaluation Ratings Close Student Achievement Gaps? The Elementary School Journal, 106, 3-22. http://dx.doi.org/10.1086/496904

Darling-Hammond, L. (2004). Standards, Accountability and School Reform. Teachers College Record, 106, $1047-1085$. http://dx.doi.org/10.1111/j.1467-9620.2004.00372.x

Darling-Hammond, L., \& Pecheone, R. (2010). Developing an Internationally Comparable Balanced Assessment System That Supports High-Quality Learning. The National Conference on Next Generation Assessment Systems.

Darling-Hammond, L., \& Youngs, P. (2002). Defining "Highly Qualified Teachers”: What Does "Scientifically-Based Research” Actually Tell Us? Educational Researcher, 31, 13-25. http://dx.doi.org/10.3102/0013189X031009013

Fenstermacher, G. D., \& Richardson, V. (2005). On Making Determinations of Quality Teaching. Teacher College Record, 107, 186-213. http://dx.doi.org/10.1111/j.1467-9620.2005.00462.x

Fullan, M., Hill, P., \& Crevola, C. (2006). Breakthrough. Thousand Oaks, CA: Corwin Press.

Hiebert, J., \& Lefevre, P. (1986). Conceptual and Procedural Knowledge in Mathematics: An Introductory Analysis. In J. 
Hiebert (Ed.), Conceptual and Procedural Knowledge: The Case of Mathematics (pp. 1-27). Hillsdale, NJ: Lawrence Erlbaum Associates.

Hosp, J. L., \& Ardoin, S. P. (2008). Assessment for Instructional Planning. Assessment for Effective Intervention, 33, 69-77. http://dx.doi.org/10.1177/1534508407311428

Hoy, W. K., \& Miskel, C. G. (2005). Educational Administration: Theory, Research, and Practice. New York: McGrawHill.

Ju-Sen, L., \& Chaoyun, L. (2014). The Perceived Influence of Learning Environment on Design Student Imagination. International Journal of Learning, Teaching and Educational Research, 2, 124-136.

Lee, V. E., \& Burkam, D. T. (2003). Dropping out of High School: The Role of School Organization and Structure. American Educational Research Journal, 40, 353-393. http://dx.doi.org/10.3102/00028312040002353

Lee, V. E., \& Smith, J. B. (1995). Effects of High School Restructuring and Size on Gains in Achievement and Engagement for Early Secondary School Students. Sociology of Education, 68, 241-270. http://dx.doi.org/10.2307/2112741

Magen-Nagar, N., \& Shachar, H. (2016). Quality of Teaching and Dropout Risk: A Multi-Level Analysis. Journal of Education for Students Placed at Risk. (In Press)

Ministry of Education, Israel (2013a). Annual Report. Goals and Objectives of the Ministry for 2009-2012. http://cms.education.gov.il/EducationCMS/Units/Hofesh/DeenVeHeshbon/2008/2008/MatarotYeadim.htm (Hebrew)

Ministry of Education, Israel (2013b). (Almost) Everything about Education Institutions. http://cms.education.gov.il/EducationCMS/Applications/IMS/HomePage.htm (Hebrew)

OECD (2013). PISA 2012 Results in Focus. What 15-Year-Olds Know and What They Can Do with What They Know. Paris: OECD.

Prevatt, F., \& Kelly, D. (2003). Dropping out of School: A Review of Intervention Programs. Journal of School Psychology, 41, 377-395. http://dx.doi.org/10.1016/S0022-4405(03)00087-6

RAMA (2013). MEITZAV_Measurements of School Efficiency and Growth-General Background. http://cms.education.gov.il/EducationCMS/Units/Rama/Meitzav/ (Hebrew)

Rumberger, R. W., \& Palardy, G. J. (2005). Test Scores, Dropout Rates, and Transfer Rates as Alternative Indicators of High School Performance. American Educational Research Journal, 42, 3-42. http://dx.doi.org/10.3102/00028312042001003

Schoenfeld, A. H. (1985). Mathematical Problem Solving. San Diego, CA: Academic Press.

Shannon, G. S., \& Bylsma, P. (2008). Helping Students Finish School: Why Students Drop out and How to Help Them Graduate. Olympia, WA: OSPI.

Tam, W. (2011). Hidden School Disengagement and Its Relationship to Youth Risk Behaviors in Hong Kong. Educational Research Journal, 26, 175-197.

Vygotsky, L. S. (2004). The Collective as a Factor in the Development of the Abnormal Child. In R. W. Rieber, \& D. K. Robinson (Eds.), The Essential Vygotsky (pp. 201-219). New York: Kluwer Academic/Plenum Publishers.

\section{Submit or recommend next manuscript to SCIRP and we will provide best service for you:}

Accepting pre-submission inquiries through Email, Facebook, LinkedIn, Twitter, etc.

A wide selection of journals (inclusive of 9 subjects, more than 200 journals)

Providing 24-hour high-quality service

User-friendly online submission system

Fair and swift peer-review system

Efficient typesetting and proofreading procedure

Display of the result of downloads and visits, as well as the number of cited articles

Maximum dissemination of your research work

Submit your manuscript at: http://papersubmission.scirp.org/ 